\title{
Enraizamento de corticeira-da-serra em função do tipo de estaca e variações sazonais
}

\author{
Tarcia dos Santos Neves ${ }^{(1)}$, Antonio Aparecido Carpanezzi(2), Katia Christina Zuffellato-Ribas ${ }^{(3)}$ \\ e Ricardo Antonio Marenco ${ }^{(1)}$
}

\begin{abstract}
(1)Instituto Nacional de Pesquisas da Amazônia (Inpa), Coordenação de Pesquisas em Silvicultura Tropical (CPST), Caixa Postal 478, CEP 69011-970 Manaus, AM. E-mail: tarcian@bol.com.br, rmarenco@inpa.gov.br (2)Embrapa Florestas, Caixa Postal 319, CEP 83411-000 Colombo, PR. E-mail: carpa@cnpf.embrapa.br (3)Universidade Federal do Paraná, Centro Politécnico, Dep. de Botânica, Caixa Postal 19031, CEP 81531-970 Curitiba, PR. E-mail: kazu@ufpr.br
\end{abstract}

Resumo - Erythrina falcata Benth. tem sido usada na recuperação de ecossistemas degradados, como planta ornamental e em sistemas agroflorestais. Entretanto, a produção de mudas por sementes é difícil. O objetivo deste trabalho foi avaliar a propagação vegetativa de E. falcata utilizando estacas caulinares provenientes de árvores adultas (estacas herbáceas, semilenhosas e de rebrota) e mudas, coletadas em quatro épocas do ano e o efeito do ácido indolbutírico (AIB) no enraizamento de estacas dessa espécie. Depois de preparadas, as estacas foram imersas em ácido indolbutírico (AIB, 0, 1,5 e $3 \mathrm{~g} \mathrm{~L}^{-1}$ ). O material se desenvolveu em tubetes de plástico ( $55 \mathrm{~mL}$ ), em casa de vegetação climatizada, a uma temperatura de 25 a $30^{\circ} \mathrm{C}$ e umidade relativa do ar acima de $80 \%$, em substrato de vermiculita granulometria média. Maior porcentagem de enraizamento (73\%), comprimento das quatro maiores raízes $(46 \mathrm{~mm})$ e número de raízes $(6,2)$ foram obtidos em estacas de mudas coletadas no verão. Não houve enraizamento em estacas semilenhosas, provenientes de árvores adultas. A imersão das estacas em AIB não exerceu qualquer influência no enraizamento. As estacas de mudas coletadas no verão são as de melhor propagação vegetativa em virtude de melhor porcentagem de enraizamento e sobrevivência.

Termos para indexação: Erythrina falcata, auxinas, estaquia, propagação vegetativa.

\section{Rooting of Brazilian coral as a function of cutting types and season of the year}

\begin{abstract}
Erythrina falcata Benth. may be used as an ornamental plant, in rehabilitation of degraded land and as a component in agroforestry systems. However seedling production from seeds is difficult. The aim of this work was to evaluate vegetative propagation of E. falcata by using stem cuttings obtained from adult trees (softwood cuttings, hardwood cuttings and regrowth cuttings) and cuttings from seedlings collected in the four seasons of the year as well as the effect of indolebutyric acid on rooting of stem cuttings. After cutting preparation, the material was treated with an indolebutyric acid solution (IBA, 0, 1.5 and $3 \mathrm{~g} \mathrm{~L}^{-1}$ ). Cuttings were grown in 55 - $\mathrm{mL}$ tapered plastic containers in a greenhouse at 25 to $30^{\circ} \mathrm{C}$ and relative humidity above $80 \%$. The substrate for growing of cuttings was middle texture vermiculite. The highest percentage of rooted cuttings (73\%) and root length of four longest roots (46 mm) and root number (6.2) were obtained in seedling cuttings collected in the summer. No rooting was observed in cuttings collected from softwood cuttings raised from adult trees. Cutting immersion in IBA solutions had no effect on rooting. Cuttings from seedlings collected in the summer are recommended because of their high percentage of rooting and survival.
\end{abstract}

Index terms: Erythrina falcata, auxins, cuttings, vegetative propagation.

\section{Introdução}

A corticeira-da-serra (Erythrina falcata Benth., Fabaceae) é uma espécie arbórea, secundária tardia, de grande porte (até $35 \mathrm{~m}$ de altura e $1 \mathrm{~m}$ de diâmetro). É encontrada no Brasil, na Argentina, na Bolívia, no Paraguai e no Peru. No Brasil, ocorre desde a Bahia até o Rio Grande do Sul, em ecossistemas que variam de florestas úmidas a florestas decíduas e semidecíduas. Também pode ser encontrada no cerradão.

Parte do interesse pelo cultivo desta espécie está relacionada ao seu valor ornamental, pois pode ser utilizada em ruas e avenidas, parques e jardins, por apresentar flores atraentes e vistosas, de grande efeito decora- 
tivo (Carvalho, 2003). E. falcata pode também ser usada em sistemas agroflorestais, na restauração da mata ciliar, em locais com surtos de inundação durante o ano, e na recuperação de ecossistemas degradados. É uma espécie de rápido crescimento, característica de espécies pioneiras ou da sucessão secundária inicial. Erythrina falcata tem potencialidade para fixar $\mathrm{N}$ e suas flores produzem néctar que é apreciado por beijaflores e outros pássaros polinizadores.

A propagação da E. falcata por sementes é difícil. Em condições naturais, somente $20 \%$ dos óvulos disponíveis produzem sementes e a relação de flores para frutos é muito baixa (em torno de 1\%). É basicamente auto-incompatível, sendo polinizada por pássaros e beija-flores (Etcheverry \& Alemán, 2005).

Muitos trabalhos têm sido desenvolvidos sobre a propagação vegetativa por estaquia em razão da necessidade de mudas em viveiros comerciais. A estaquia é um método de propagação vegetativa que possui a vantagem de garantir a seleção de genótipos superiores, além da maior produção de mudas em menor espaço de tempo. As desvantagens da estaquia incluem a dificuldade de se induzir a produção de raízes adventícias em muitas espécies, bem como a diminuição da capacidade de enraizamento, como a ontogenia da planta (e.g., Eucalyptus spp.), o que torna difícil a produção de raízes em estacas maduras. Sob este aspecto, o tratamento das estacas com auxinas, principalmente ácido indolbutírico (AIB) é prática bastante difundida.

No Brasil, as pesquisas sobre estaquia envolvendo Erythrina têm comumente usado estacas de $15 \mathrm{~cm}$ ou menos, refletindo a tradição nacional para as espécies lenhosas (Carpanezzi et al., 2001). Em E. crista-galli L., o enraizamento é maior em estacas jovens e finas (3 a $6 \mathrm{~mm}$ ) obtidas de brotações de estacas mais grossas. A propagação vegetativa de $E$. falcata por estaquia é uma alternativa de produção de mudas, mas há pouca informação sobre a técnica de propagação.

Órgãos em crescimento ativo apresentam maiores concentrações de auxinas (e.g., ácido indolacético) e tipos de estacas diferentes do ponto de vista fisiológico (idades) apresentam taxas de enraizamento variáveis. Desse modo, a quantidade de auxina exógena necessária para induzir o enraizamento deveria ser menor em estacas mais jovens. Em climas temperados, muitas espécies cessam seu crescimento na época mais fria, reiniciando-o na primavera conforme a duração do dia e a temperatura aumentam. O rejuvenescimento das plantas pode ser induzido por vários métodos, incluindo a enxertia seriada (Huang et al., 1992) e poda. A poda, por exemplo, estimula a desdiferenciação e posterior rediferenciação das células do câmbio, promovendo a formação de gemas.

O objetivo deste trabalho foi avaliar a propagação vegetativa de estacas caulinares de Erythrina falcata provenientes de árvores adultas e mudas, coletadas nas quatro épocas do ano e o efeito do ácido indolbutírico (AIB) no enraizamento de estacas dessa espécie.

\section{Material e Métodos}

O trabalho foi realizado na Embrapa Florestas, Município de Colombo, PR, de outubro de 2003 a dezembro de 2004. As coletas foram realizadas no período da manhã, em quatro épocas do ano. As coletas de material vegetativo foram realizadas em outubro e dezembro (primavera), janeiro e março (verão), abril e junho (outono) e julho (inverno). Foram realizadas duas coletas por época porque alguns tipos de estacas não estiveram disponíveis em todos os meses do ano. Em julho (inverno), somente houve acesso a estacas semilenhosas. Foram utilizadas estacas de árvores adultas (herbáceas, semilenhosas e estacas de rebrota) e estacas de mudas oriundas de sementes.

As estacas herbáceas foram obtidas da parte apical de brotações do ano de árvores adultas, desprezandose o ápice. O comprimento e diâmetro dessas estacas foi de 15 e $0,8 \mathrm{~cm}$, respectivamente. Em cada estaca desse tipo, foram mantidos dois pares de folhas reduzidas à metade. As estacas semilenhosas foram retiradas da parte intermediária de ramos de brotações do ano, e preparadas com $15 \mathrm{~cm}$ de comprimento e $0,8 \mathrm{~cm}$ de diâmetro. Essas estacas foram as únicas que não possuíam folhas. As estacas de rebrota, com $15 \mathrm{~cm}$ de comprimento e $1,0 \mathrm{~cm}$ de diâmetro, foram retiradas de brotações jovens de ramos de árvores adultas podados na estação anterior. Nestas estacas também foram mantidos dois pares de folhas reduzidas à metade. As estacas oriundas de mudas de sete meses de idade e até $50 \mathrm{~cm}$ de altura foram preparadas com $6,0 \mathrm{~cm}$ de comprimento e $0,9 \mathrm{~cm}$ de diâmetro, com dois pares de folhas reduzidas à metade. $\mathrm{O}$ ápice das mudas não foi incluído na formação da estaca.

As estacas de brotações do ano (herbáceas e semilenhosas) e as estacas de rebrota foram coletadas de 15 árvores nativas, com cerca de 20 anos de idade, no Município de Tunas do Paraná, PR. Estas estacas foram envoltas em papel umedecido e transportadas em 
caixas de plástico até o local de preparo. As estacas de mudas oriundas de sementes provinham de mudas cultivadas no viveiro da Embrapa Florestas. Depois de sua confecção, as estacas foram desinfestadas com hipoclorito de sódio (0,5\%) e solução de benomil $\left(0,5 \mathrm{~g} \mathrm{~L}^{-1}\right)$. Os primeiros $3 \mathrm{~cm}$ da parte basal das estacas, de todos os tipos, foram imersos por 10 s numa solução alcoólica (50\%) de AIB nas concentrações de $0,1,5$ e $3 \mathrm{~g} \mathrm{~L}^{-1}$. As estacas foram plantadas em tubetes cônicos de polipropileno com volume de $55 \mathrm{~cm}^{3}$, dispostos em bandejas de $12 x 8$ células, contendo vermiculita de granulometria média. Os tubetes foram acondicionados em casa de vegetação climatizada com nebulização intermitente. A temperatura esteve entre 25 e $30^{\circ} \mathrm{C}$ e a umidade relativa do ar acima de $80 \%$, esta última, controlada por um sensor de umidade. Na instalação do experimento, e depois de 30 dias, o ápice de todas as estacas foi pincelado com solução de benomil (1\%) em lanolina, para evitar ataque de microrganismos ou insetos.

Os experimentos foram conduzidos em delineamento inteiramente casualizado, com quatro tipos de estacas, três concentrações de AIB e quatro repetições. Este experimento foi repetido nas quatro épocas. A unidade experimental foi constituída por 24 estacas para os tipos herbáceos e semilenhosos, 13 estacas para o tipo estaca de rebrota e 20 estacas para o tipo estacas de mudas. As estacas herbáceas, semilenhosas e de rebrota foram avaliadas durante 80 dias, enquanto as estacas de mudas, durante 45 dias. Isto porque a maioria das estacas oriundas de mudas produziram raízes em poucas semanas, o que determinava o encerramento do experimento. Para compensar a falta de alguns tipos de estacas na primavera de 2003, o período de coletas de material estendeu-se até a primavera de 2004, encerrando-se a coleta de dados em dezembro daquele ano. No verão houve disponibilidade de estacas de mudas, somente em janeiro (verão). Analogamente, em junho não foram investigadas estacas de rebrota e mudas e em julho foram avaliadas somente estacas semilenhosas.

Foram avaliadas as seguintes variáveis: percentagem de estacas enraizadas, estacas vivas e com indução de primórdios radiculares de no mínimo $1 \mathrm{~mm}$ de comprimento, podendo ou não apresentar calos; número médio de raízes por estaca; comprimento médio das quatro maiores raízes por estaca; porcentagem de estacas com calos, estacas vivas, sem raízes e com formação de massa celular indiferenciada na base; porcentagem de estacas vivas, estacas vivas, mas sem indução de primórdio radicular e sem formação de calos; porcentagem de estacas mortas.

Antes de as análises estatísticas serem efetuadas, os dados foram transformados. Dados expressos em porcentagem foram transformados em arc sen $(y)^{0,5}$, enquanto os outros dados (comprimento de raiz e número de raízes) foram transformados em $\log (y+1)$. Devido ao efeito marcante das estações do ano sobre as variáveis estudadas, a relação entre os quadrados médios residuais, máximos $\left(\mathrm{QMR}_{\text {máx }}\right)$ e mínimos $\left(\mathrm{QMR}_{\min }\right)$ foi utilizada como critério para agrupar experimentos (estações do ano). Duas estações com $\mathrm{QMR}_{\text {máx }} / \mathrm{QMR}_{\text {mín }}$ igual ou menor que sete foram agrupadas e analisadas como um fatorial (estação $\mathrm{x}$ tipo de estaca $\mathrm{x}$ concentração de AIB). Os dados foram analisados por meio do programa SAEG da UFV. A comparação das médias foi feita utilizando-se o teste de Tukey.

\section{Resultados e Discussão}

As variáveis porcentagem de estacas vivas que não produziram raízes e nem calos (PV), porcentagem de estacas mortas (PM) e porcentagem de calo (PC) medidas na primavera, verão e outono foram analisadas em conjunto $\left(\mathrm{QMR}_{\text {máx }} / \mathrm{QMR}_{\text {mín }}<7\right)$. Somente foi possível agrupar dados da primavera e do verão para as variáveis porcentagem de enraizamento (PE), comprimento das maiores quatro raízes (CMR) e número de raízes (NRA). Dados do inverno foram examinados em separado.

A porcentagem de estacas vivas que não produziram raízes e nem calos (PV) foi maior nas estacas herbáceas e semilenhosas oriundas de árvores adultas nas coletas efetuadas no outono (26 a 34\%), quando comparadas aos outros tipos (Tabela 1). Nessa época do ano, a PV foi nula para estacas oriundas de mudas. Analogamente, a mortalidade também foi elevada (85 a 90\%) nas estacas semilenhosas coletadas na primavera e verão ou no inverno. Em estacas de rebrota, a maior mortalidade foi na primavera e outono. Independentemente da época, as estacas de mudas apresentaram os menores porcentuais de mortalidade.

A maior porcentagem de enraizamento foi obtida em estacas oriundas de mudas coletadas no verão (73\%), seguida pelo outono e primavera. Não ocorreu enraizamento nas estacas semilenhosas independentemente da época do ano em que foi efetuada a coleta (Tabela 1). O comprimento das quatro maiores raízes 
foi maior em estacas oriundas de mudas (verão e outono) e de rebrotas nas coletas efetuadas no verão (46 a $52 \mathrm{~mm}$ ). O número de raízes foi maior nas três épocas do ano em que foram coletadas estacas de mudas, e obtiveram-se cinco a seis raízes por estaca.

O efeito da época do ano na capacidade de enraizamento de estacas também foi verificado por Ercisli et al. (2003), que observaram maior porcentagem de enraizamento em estacas de kiwi (Actinidia deliciosa [A. Chev.] CF Liang et AR Ferguson, Actinidiaceae) em coletas efetuadas em fevereiro, o que provavelmente está relacionado ao efeito da luminosidade e temperatura no enraizamento das estacas (Fogaça \& Fett-Neto, 2005). Por exemplo, em Eucalyptus saligna Smith (Myrtaceae), as baixas temperaturas $\left(15^{\circ} \mathrm{C}\right)$ inibem a formação de raízes (Correa \& Fett-Neto, 2004).

Tabela 1. Efeito do tipo de estaca e estação do ano na porcentagem de estacas vivas que não produziram raízes nem calos, porcentagem de estacas mortas, de calo, de enraizamento, comprimento da maior raiz e número de raízes, em Erythrina falcata ${ }^{(1)}$.

\begin{tabular}{|c|c|c|c|c|}
\hline Tipo & Primavera & Verão & Outono & Inverno \\
\hline & \multicolumn{4}{|c|}{ Porcentagem de estacas vivas ${ }^{(2)}$} \\
\hline Herbácea & $6,3 \mathrm{aB}$ & $7,3 \mathrm{bcB}$ & $33,7 \mathrm{aA}$ & - \\
\hline Semilenhosa & $7,8 \mathrm{aB}$ & $2,6 \mathrm{cB}$ & $26,4 \mathrm{aA}$ & 5,9 \\
\hline Estaca de muda & $6,7 \mathrm{aB}$ & $10,8 \mathrm{abA}$ & $0,0 \mathrm{bB}$ & - \\
\hline \multirow[t]{2}{*}{ Rebrota } & $0,5 \mathrm{bC}$ & $21,8 \mathrm{aA}$ & $9,7 \mathrm{bB}$ & - \\
\hline & \multicolumn{4}{|c|}{ Porcentagem de estacas mortas ${ }^{(2)}$} \\
\hline Herbácea & $86,9 \mathrm{aA}$ & $84,5 \mathrm{aA}$ & $60,1 \mathrm{bB}$ & - \\
\hline Semilenhosa & $90,2 \mathrm{aA}$ & $85,2 \mathrm{aA}$ & $70,4 \mathrm{bB}$ & 94,1 \\
\hline Estaca de muda & $39,1 \mathrm{bA}$ & $13,3 \mathrm{cB}$ & $23,6 \mathrm{cAB}$ & - \\
\hline \multirow[t]{2}{*}{ Rebrota } & $94,1 \mathrm{aA}$ & $51,5 \mathrm{bB}$ & $90,3 \mathrm{aA}$ & - \\
\hline & \multicolumn{4}{|c|}{ Porcentagem de calo ${ }^{(2)}$} \\
\hline Herbácea & $1,0 \mathrm{bB}$ & 7,1abA & $6,3 \mathrm{bA}$ & - \\
\hline Semilenhosa & $2,0 \mathrm{abB}$ & $12,2 \mathrm{aA}$ & $3,1 \mathrm{bcB}$ & 0,0 \\
\hline Estaca de muda & $6,5 \mathrm{aB}$ & $2,5 \mathrm{bB}$ & $19,4 \mathrm{aA}$ & - \\
\hline \multirow[t]{2}{*}{ Rebrota } & $0,0 \mathrm{bB}$ & $6,4 \mathrm{abA}$ & $0,0 \mathrm{cB}$ & - \\
\hline & \multicolumn{4}{|c|}{ Porcentagem de enraizamento ${ }^{(2)}$} \\
\hline Herbácea & $5,8 \mathrm{bA}$ & $1,0 \mathrm{cB}$ & $0,0 \mathrm{~b}$ & - \\
\hline Semilenhosa & $0,0 \mathrm{cA}$ & $0,0 \mathrm{cA}$ & $0,0 \mathrm{~b}$ & 0,0 \\
\hline Estaca de muda & $47,6 \mathrm{aB}$ & $73,3 \mathrm{aA}$ & $56,9 \mathrm{a}$ & - \\
\hline \multirow[t]{2}{*}{ Rebrota } & $5,3 \mathrm{bB}$ & $20,4 \mathrm{bA}$ & $0,0 \mathrm{~b}$ & - \\
\hline & \multicolumn{4}{|c|}{ Comprimento da maior raiz ${ }^{(3)}$} \\
\hline Herbácea & $12,4 \mathrm{bA}$ & $12,8 \mathrm{bA}$ & $0,0 \mathrm{~b}$ & - \\
\hline Semilenhosa & $0,0 \mathrm{cA}$ & $0,0 \mathrm{bA}$ & $0,0 \mathrm{~b}$ & 0,0 \\
\hline Estaca de muda & $10,5 \mathrm{aB}$ & $46,3 \mathrm{aA}$ & $47,1 \mathrm{a}$ & - \\
\hline \multirow[t]{2}{*}{ Rebrota } & $2,6 \mathrm{bB}$ & $52,1 \mathrm{aA}$ & $0,0 \mathrm{~b}$ & - \\
\hline & \multicolumn{4}{|c|}{ Número de raízes ${ }^{(3)}$} \\
\hline Herbácea & $2,1 \mathrm{bA}$ & $0,7 \mathrm{cB}$ & $0,0 \mathrm{~b}$ & - \\
\hline Semilenhosa & $0,0 \mathrm{cA}$ & $0,0 \mathrm{cA}$ & $0,0 \mathrm{~b}$ & 0,0 \\
\hline Estaca de muda & $4,6 \mathrm{aA}$ & $6,2 \mathrm{aA}$ & $4,6 \mathrm{a}$ & - \\
\hline Rebrota & $1,6 \mathrm{bB}$ & $4,2 \mathrm{bA}$ & $0,0 \mathrm{~b}$ & - \\
\hline
\end{tabular}

(1)Médias seguidas das mesmas letras, minúsculas nas colunas e maiúsculas nas linhas, não diferem entre si pelo teste de Tukey, a 5\% de probabilidade. ${ }^{(2)}$ Dados transformados em arc sen $\left(\mathrm{y}^{0,5}\right)$, para a análise estatística. (3)Dados transformados em $\log (\mathrm{y}+1)$, para a análise estatística.
A baixa porcentagem de enraizamento de estacas oriundas de árvores adultas pode ter ocorrido em razão da diminuição da capacidade de formar raízes com o aumento da idade, pois, ramos maduros tendem a ter menor concentração de auxina (Hartmann et al., 2002; Xavier, 2002). Outra causa poderia ser a falta de capacidade das células para receber o estímulo hormonal (Trewavas \& Cleland, 1983).

As estacas herbáceas e semilenhosas de E. falcata podem sofrer com as temperaturas altas da primavera e do verão. Isto porque, conforme a irradiância e a temperatura aumentam, aumenta também a transpiração (Marenco et al., 2001; Marenco \& Lopes, 2005). Em outubro de 2003, houve indução de brotação uma semana depois da instalação do experimento, mas tanto as brotações como as estacas morreram cerca de 30 dias mais tarde, provavelmente porque as folhas recém-formadas contribuíram para a perda de água por transpiração, dessecando o tecido e levando à morte da estaca. Isto porque a taxa de transpiração da folha continua alta mesmo com umidade relativa do ar acima de 80\% (Marenco \& Lopes, 2005), como era a condição em casa de vegetação.

As espécies de difícil enraizamento provavelmente também apresentam baixo teor de auxinas (Norberto et al., 2001). A concentração do regulador vegetal varia de acordo com a espécie, cultivar e tipo de estaca. As estacas possuem certa quantidade endógena de hormônios promotores ou inibidores de enraizamento, mas é necessário que haja um balanceamento adequado entre auxinas, giberelinas e citocininas e co-fatores de enraizamento para que haja enraizamento. Desse modo, o fornecimento de auxina exógena pode promover alteração hormonal, favorecendo ou não o enraizamento (Ramos et al., 2003).

As estacas de mudas coletadas em outubro continuaram com folhas, ao longo do experimento (80 dias), o que não ocorreu com as estacas herbáceas. Independentemente da época do ano, estacas oriundas de mudas também apresentaram os melhores resultados em Robinia pseudoacacia L. e Grewia optiva Drumm. (Swamy et al., 2002).

Em comparação com as estacas herbáceas e semilenhosas, as estacas oriundas de rebrota apresentaram bom desempenho no que se refere à porcentagem de enraizamento. Essas estacas mantiveram as folhas, o que, provavelmente, contribuiu para o sucesso no enraizamento, pois as folhas são fontes de auxina e de carboidratos (Hartmann et al., 2002). No verão, as 
estacas de rebrota começaram a enraizar com 35 dias, e apresentaram um sistema radicular vigoroso. Assim, uma alternativa para favorecer o enraizamento em plantas tradicionalmente de difícil enraizamento seria manter as estacas na condição juvenil por meio de podas sucessivas. Além disso, esse procedimento permite aumentar a produção de propágulos, sem excluir o rejuvenescimento das plantas via enxertia seriada (Huang et al., 1992) ou poda.

Os resultados obtidos confirmam a hipótese de Xavier (2002), que considera que a época do ano é muito importante para o enraizamento de estacas, pois as condições fisiológicas da planta matriz podem ser influenciadas pelas variações sazonais. Além disso, o fator genético parece ser determinante para o sucesso da propagação vegetativa. Em Calliandra calothyrsus, a capacidade de produzir raízes variou conforme a origem das matrizes (Dick et al., 1996).

A maior parte das estacas herbáceas do outono manteve suas folhas até o final do experimento (80 dias), o que geralmente não aconteceu no verão. No outono, as estacas possuem reservas de carboidratos, mas também podem possuir inibidores do enraizamento, o que dificultaria a formação de raízes (Hartmann et al., 2002). Com relação às coletas efetuadas no outono, os dias curtos dessa estação, e as temperaturas baixas do ambiente exercem influência negativa no processo fotossintético das árvores matrizes. Todas as estacas, à exceção das semilenhosas, possuíam folhas. Provavelmente a presença de folhas contribuiu para o melhor desempenho daquelas estacas, pois as folhas fornecem carboidratos, hormônios e outras substâncias que estimulam o crescimento de raízes adventícias (Scaloppi Junior et al., 2004). A importância das reservas de carboidratos nas estacas foi demonstrada em Cornus canadensis L., em cuja espécie, estacas com rizomas produziram maior número de brotações (Haynes \& Smagula, 2003). Além disso, estacas oriundas de mudas tendem a enraizar mais facilmente, pois se presume que estão fisiologicamente favoráveis ao enraizamento (Hartmann et al., 2002).

No inverno, dias curtos e baixas temperaturas alteram processos fisiológicos (e.g., fotossíntese, transporte de compostos e substâncias) das árvores matrizes, o que pode dificultar o enraizamento das estacas obtidas. A porcentagem de enraizamento diminui com a proximidade do inverno, quando os níveis de ácido abscísico (ABA) são normalmente altos. Essa queda na capacidade de enraizamento pode dever-se a variações no conteúdo de co-fatores ou à formação e acúmulo de inibidores de enraizamento (Nachtigal et al., 1999; Tofanelli et al., 2002).

O tratamento com AIB não incrementou a indução de raízes ou a formação de calos, nem contribuiu para aumentar o comprimento da raiz, independentemente do tipo de estaca (Tabela 2). Isto está de acordo com o relatado por Ofori et al. (1996), que não encontraram resposta no enraizamento de estacas de Milicia excelsa (Welw.) CC Berg (Moraceae), quando tratadas com uma solução de AIB de até $16 \mathrm{~g} \mathrm{~L}^{-1}$. Ao contrário, Aminah et al. (1995) encontraram que a aplicação de $20 \mu \mathrm{g}$ de AIB por estaca estimulou o enraizamento em $70 \%$ das estacas de Shorea leprosula Miq. (Dipterocarpaceae). A inexistência de efeito do AIB pode indicar várias possibilidades: alta concentração de auxina no tecido (provavelmente isso aconteceu em mudas); pouca sensibilidade do tecido à presença de auxinas (Trewavas \& Cleland, 1983). Uma outra possibilidade é que as concentrações usadas foram muito baixas, embora concentrações de $9 \mathrm{~g} \mathrm{~L}^{-1}$ já tenham sido testadas sem sucesso no estímulo do enraizamento de estacas

Tabela 2. Porcentagem de estacas vivas que não possuíam raízes e nem calos, porcentagem de mortalidade, de calo, de enraizamento, comprimento da maior raiz e número de raízes, em função da concentração de AIB em Erythrina falcata(1).

\begin{tabular}{|c|c|c|c|c|}
\hline $\operatorname{AIB}\left(\mathrm{g} \mathrm{L}^{-1}\right)$ & Herbácea & Semilenhosa & $\begin{array}{c}\text { Estaca de } \\
\text { muda }\end{array}$ & Rebrota \\
\hline & \multicolumn{4}{|c|}{ Porcentagem de estacas vivas ${ }^{(2)}$} \\
\hline 0,0 & $11,3 \mathrm{a}$ & $8,0 \mathrm{a}$ & $7,9 \mathrm{a}$ & $9,2 \mathrm{a}$ \\
\hline 1,5 & $15,3 \mathrm{a}$ & $10,9 \mathrm{a}$ & $5,0 \mathrm{a}$ & $12,8 \mathrm{a}$ \\
\hline \multirow[t]{2}{*}{3,0} & $13,5 \mathrm{a}$ & $12,8 \mathrm{a}$ & $5,7 \mathrm{a}$ & $10,5 \mathrm{a}$ \\
\hline & \multicolumn{4}{|c|}{ Porcentagem de estacas mortas ${ }^{(2)}$} \\
\hline 0,0 & $83,7 \mathrm{a}$ & $88,4 \mathrm{a}$ & $37,4 \mathrm{a}$ & $79,6 \mathrm{a}$ \\
\hline 1,5 & $75,9 \mathrm{a}$ & $85,1 \mathrm{a}$ & $28,1 \mathrm{a}$ & $72,3 a$ \\
\hline \multirow[t]{2}{*}{3,0} & $79,1 \mathrm{a}$ & $81,8 \mathrm{a}$ & $27,2 \mathrm{a}$ & $77,0 \mathrm{a}$ \\
\hline & \multicolumn{4}{|c|}{ Porcentagem de calo ${ }^{(2)}$} \\
\hline 0,0 & $3,0 \mathrm{a}$ & $3,6 \mathrm{a}$ & $5,2 \mathrm{a}$ & $2,4 \mathrm{a}$ \\
\hline 1,5 & $4,0 \mathrm{a}$ & $3,9 a$ & $11,9 \mathrm{a}$ & $2,1 \mathrm{a}$ \\
\hline \multirow[t]{2}{*}{3,0} & $4,5 \mathrm{a}$ & $5,3 \mathrm{a}$ & $7,7 \mathrm{a}$ & $3,2 \mathrm{a}$ \\
\hline & \multicolumn{4}{|c|}{ Porcentagem de enraizamento ${ }^{(2)}$} \\
\hline 0,0 & $1,9 \mathrm{a}$ & $0,0 \mathrm{a}$ & $49,5 \mathrm{a}$ & $8,7 \mathrm{a}$ \\
\hline 1,5 & $4,7 \mathrm{a}$ & $0,0 \mathrm{a}$ & $55,0 \mathrm{a}$ & $12,8 \mathrm{a}$ \\
\hline \multirow[t]{2}{*}{3,0} & $2,8 \mathrm{a}$ & $0,0 \mathrm{a}$ & $59,3 \mathrm{a}$ & $9,3 \mathrm{a}$ \\
\hline & \multicolumn{4}{|c|}{ Comprimento da maior raiz ${ }^{(3)}$} \\
\hline 0,0 & $7,4 \mathrm{a}$ & $0,0 \mathrm{a}$ & $26,5 \mathrm{a}$ & $22,1 \mathrm{a}$ \\
\hline 1,5 & $15,4 \mathrm{a}$ & $0,0 \mathrm{a}$ & $26,5 \mathrm{a}$ & $17,8 \mathrm{a}$ \\
\hline \multirow[t]{2}{*}{3,0} & $5,3 \mathrm{a}$ & $0,0 \mathrm{a}$ & $21,9 \mathrm{a}$ & $25,7 \mathrm{a}$ \\
\hline & \multicolumn{4}{|c|}{ Número de raízes ${ }^{(3)}$} \\
\hline 0,0 & $0,8 \mathrm{a}$ & $0,0 \mathrm{a}$ & $4,1 \mathrm{a}$ & $2,0 \mathrm{a}$ \\
\hline 1,5 & $1,6 \mathrm{a}$ & $0,0 \mathrm{a}$ & $5,2 \mathrm{a}$ & $1,7 \mathrm{a}$ \\
\hline 3,0 & $1,3 \mathrm{a}$ & $0,0 \mathrm{a}$ & $5,5 \mathrm{a}$ & $3,2 \mathrm{a}$ \\
\hline
\end{tabular}

${ }^{(1)}$ Médias seguidas das mesmas letras nas colunas não diferem entre si pelo teste de Tukey, a $5 \%$ de probabilidade. (2)Dados transformados em arc sen $\left(y^{0,5}\right)$, para a análise estatística. ${ }^{(3)}$ Dados transformados em $\log (y+1)$, para a análise estatística. 
semilenhosas dessa mesma espécie (Rêgo et al., 2003). Os efeitos benéficos do AIB no enraizamento de estacas têm sido bem documentados (Mesén et al., 1997; Pan \& Tian, 1999) mas também há relatos nos quais o AIB tem sido ineficaz na indução do enraizamento (Ofori et al., 1996).

\section{Conclusões}

1. A estação do ano em que as estacas são coletadas é fator determinante para seu enraizamento e sobrevivência.

2. Independentemente da estação, as estacas oriundas de mudas apresentam o maior porcentual de enraizamento.

3. O AIB não tem efeito significativo no enraizamento nem na sobrevivência de estacas de Erythrina falcata, independentemente do tipo de estacas e da época do ano.

\section{Agradecimentos}

À Embrapa Florestas, pelo financiamento da pesquisa; ao $\mathrm{CNPq}$, pela bolsa concedida a Ricardo Antonio Marenco; ao Inpa; à Fapeam; ao Dr. Antonio Aparecido Carpanezzi, pelo apoio à realização da pesquisa.

\section{Referências}

AMINAH, H.; DICK, J.McP.; LEAKEY, R.R.B.; GRACE, J.; SMITH, R.I. Effect of indole butyric acid (IBA) on stem cuttings of Shorea leprosula. Forest Ecology and Management, v.72, p.199206, 1995.

CARPANEZZI, A.A.; TAVARES, F.R.; SOUSA, V.A. de. Estaquia de corticeira-do-banhado (Erythrina crista-galli L.). Colombo: Embrapa Florestas, 2001. 6p. (Embrapa Florestas. Comunicado técnico, 64).

CARVALHO, P.E.R. Espécies arbóreas brasileiras. Brasília: Embrapa Informação Tecnológica; Colombo: Embrapa Florestas, 2003. v.2. 1036p.

CORRÊA, L.R. da; FETT-NETO, A.G. Effects of temperature on adventitious root development in microcuttings of Eucalyptus saligna Smith and Eucalyptus globulus Labill. Journal of Thermal Biology, v.29, p.315-324, 2004.

DICK, J.M.; BISSET, H.; McBEATH, C. Provenance variation in rooting ability of Calliandra calothirsus. Forest Ecology and Management, v.87, p.175-184, 1996.

ERCISLI, S.; ESITKEN, A.; CANGI, R.; SAHIN, F. Adventitious root formation of kiwifruit in relation to sampling date, IBA and Agrobacterium rubi inoculation. Plant Growth Regulation, v.41, p.133-137, 2003.
ETCHEVERRY, A.V.; ALEMÁN, C.E.T. Reproductive biology of Erithrina falcata (Fabaceae: Papilionoideae). Biotrópica, v.37, p.5463, 2005.

FOGAÇA, C.M.; FETT-NETO, A.G. Role of auxin and its modulators in the adventitious rooting of Eucalyptus species differing in recalcitrance. Plant Growth Regulation, v.45, p.1-10, 2005.

HARTMANN, H.T.; KESTER, D.E.; DAVIES JUNIOR, F.T.; GENEVE, R.L. Plant propagation: principles and practices. $7^{\text {th }}$ ed. Upper Saddle River: Prentice Hall, 2002. 880p.

HAYNES, J.G.; SMAGULA, J.M. Rooting and establishment of bunchberry stem cuttings as affected by propagation date, K-IBA, rooting duration, and by division or cuttage. HortScience, v.38, p.92-96, 2003.

HUANG, L.C.; LIUS, S.; HUANG, B.-L.; MURASHIGE, T.; MAHDI, E.F.M.; VAN GUNDY, R. Rejuvenation of Sequoia sempervirens by repeated grafting of shoot tips onto juvenile rootstocks in vitro. Plant Physiology, v.98, p.166-173, 1992.

MARENCO, R.A.; GONÇALVES, J.F.C.; VIEIRA, G. Leaf gas exchange and carbohydrates in tropical trees differing in successional status in two light environments in central Amazonia. Tree Physiology, v.21, p.1311-1318, 2001.

MARENCO, R.A.; LOPES, N.F. Fisiologia vegetal: fotossíntese, respiração, relações hídricas e nutrição mineral. Viçosa: UFV, 2005. 451p.

MESÉN, F.; NEWTON, A.C.; LEAKEY, R.R.B. Vegetative propagation of Cordia alliodora (Ruiz \& Pavon) Oken: the effects of IBA concentration, propagation medium and cutting origin. Forest Ecology and Management, v.92, p.45-54, 1997.

NACHTIGAL, J.C.; PEREIRA, F.M.; DALL’ORTO, F.A.C.; OJIMA, M.; MARTINS, F.P. Propagação vegetativa do umezeiro (Prunus mume) por meio de estacas herbáceas. Revista Brasileira de Fruticultura, v.21, p.226-228, 1999.

NORBERTO, P.M.; CHALFUN, N.N.J.; PASQUAL, M.; VEIGA, R.D.; PEREIRA, G.E.; MOTA, J.H. Efeito da época de estaquia e do AIB no enraizamento de estacas de figueira (Ficus carica L.). Ciência e Agrotecnologia, v.25, p.533-541, 2001.

OFORI, D.A.; NEWTON, A.C.; LEAKEY, R.R.B.; GRACE, J. Vegetative propagation of Milicia excelsa by leafy stem cutting: effects of auxin concentration, leaf area and rooting medium. Forest Ecology and Management, v.84, p.39-48, 1996.

PAN, R.; TIAN, X.S. Comparative effect of IBA, BSAA and 5,6-CI - -IAA-Me on the rooting of hypocotyl in mung bean. Plant Growth Regulation, v.27, p.91-98, 1999.

RAMOS, J.D.; MATOS, L.E.S.; GONTIJO, T.C.A.; PIO, R.; JUNQUEIRA, K.P.; SANTOS, F.C. Enraizamento de estacas herbáceas de 'Mirabolano' (Prunus cerasifera Ehrn) em diferentes substratos e concentrações de ácido indolbutírico. Revista Brasileira de Fruticultura, v.25, p.189-191, 2003.

RÊGO, G.M.; ZUFFELLATO-RIBAS, K.C.; SILVA, C.A.C. Enraizamento de estacas caulinares da corticeira-do-seco (Erythrina falcata (Benth) - Fabaceae). Informativo Abrates, v.13, p.65, 2003. SCALOPPI JUNIOR, E.J.; JESUS, N. de; MARTINS, A.B.G. Capacidade de enraizamento de variedades de nespereira submetidas 
à poda de renovação. Revista Brasileira de Fruticultura, v.26, p.61-64, 2004.

SWAMY, S.L.; PURI, S.; SINGH, A.K. Effect of auxins (IBA and NAA) and season on rooting of juvenile and mature hardwood cuttings of Robinia pseudoacacia and Grewia optiva. New Forests, v.23, p.143-157, 2002.

TOFANELLI, M.B.D.; CHALFUN, N.N.J.; HOFFMANN, A.; CHALFUN JUNIOR, A. Efeito do ácido indolbutírico no enraizamento de estacas de ramos semilenhosos de pessegueiro. Pesquisa Agropecuária Brasileira, v.37, p.939-944, 2002.

TREWAVAS, A.J.; CLELAND, R.E. Is plant development regulated by changes and the concentration of growth substances or by changes in the sensitivity to growth substances? Trends in Biochemical Sciences, v.8, p.354-357, 1983.

XAVIER, A. Silvicultura clonal I: princípios e técnicas de propagação vegetativa. Viçosa: UFV, 2002. 64p.

Recebido em 8 de dezembro de 2005 e aprovado em 20 de setembro de 2006 